\title{
Simulation of Dam-Break Flood Wave and Inundation Mapping: A Case study of Attabad Lake
}

\author{
Wasim Karam ${ }^{1}$, Fayaz A. Khan ${ }^{2}$, Muhammad Alam ${ }^{3}$, Sajjad Ali ${ }^{4}$ \\ ${ }^{1}$ Lab. Engineer, Department of Civil Engineering, University of Engineering and Technology Mardan, Pakistan, \\ wasim10karam@gmail.com \\ ${ }^{2}$ Assistant Professor, National Institute of Urban Infrastructure Planning, University of Engineering and Technology Peshawar, \\ Pakistan, fayazuet@yahoo.com \\ ${ }^{3,4}$ Assistant Professor, Department of Civil Engineering, University of Engineering and Technology Mardan, Pakistan, \\ emalam82@gmail.com, sajjadali@uetmardan.edu.pk
}

\begin{abstract}
The break study of Landslide or embankment dams is more essential due to uncertainty in their composition and lack of knowledge of their response to other natural events because they are natural and not properly designed for any disaster. The paper aims to improve different methods of hydraulic modeling of dam break. In this present study dam break of Attabad lake is simulated using the computational fluid dynamics technique. The numerical model (FLOW-3D) is developed to solve the Reynolds averaged Navier-Stoke equation fully in $3 \mathrm{D}$ to predict peak flow depth at different cross-sections, peak velocity, peak discharge, time to peak depth, and time to peak discharge. The standard RNG turbulence model is employed to simulate turbulence and then flood inundation maps and velocity vectors for flow at villages are drawn. The results show that most of the flood wave modeled through the Hunza river channel, is contained by the flood plain of Hunza River but for some of the villages i.e. Miaun and chalat, which are situated inside the flood plain of Hunza River are at higher risk of inundation but the flood arrival time estimated for these villages is 31 and $44 \mathrm{~min}$ respectively which is enough time for the evacuation of the population to safer areas while for some villages like Hassan Abad situated adjacent to Ali Abad is at higher risk of inundation while the estimated flood arrival time for the village is $12 \mathrm{~min}$ which are not enough for the evacuation of the population hence will need some extra flood protection structures for flood containment. The estimate of the peak velocities implies higher shear stress in the river plain, risk of heavy erosion, damage to agricultural lands, residencies, and morphological changes are projected. The analysis of the dam break i.e. Peak depths, Peak Velocities, flood arrival time, and flood inundation maps should only be used as a guide in future risk analysis and flood management.
\end{abstract}

Key words: Attabad Lake, Computational Fluid Dynamics, Dam Break Simulation, FLOW-3D, Flood inundation Mapping, Navier stokes equation, Three dimensional Model.

\section{INTRODUCTION}

To establish sustainable management of the water resources dams are much necessary. Dams are constructed to obstruct the flow path of a river stream and make good use of the water that is ponded upstream of the structure. Dams can be classified in many ways, Based on the material of the dam, dams are classified into embankment dams, concrete dams, and masonry dams [1]. More of the same a lake is a natural pool of water caused by blockage of the river or underground stream.

Dam serves a variety of purposes such as water supply for irrigation, for drinking purposes, flood protection and generation of electric power, recreation and navigation, etc. [2]. However, despite all the safety that is incurred in its design, there always lies a risk of breaching in dams. Dams may fail due to large earthquakes, insufficient spillway capacity, piping, seepage, and extreme storms [3]. A dam break is a complete or incomplete catastrophic failure of a dam that causes an uncontrolled release of water. The flood wave travels at a very high speed in the downstream reach of the channel. Dam Breaks has some devastating consequences including damage to property and infrastructure, loss of life. On the other hand, it also possess some serious ecological impacts. [4]

The most common concern about dam break failures is that they are abrupt which causes immediate flooding downstream of the dam which leaves very little time for evacuation of residents or protection of the property. In contrast flooding from the rainfall or snowmelt can be predicted days or weeks in advance. That's why Dam breaks kill thousands of people across the globe. Some notable dam breaks are Malpasset dam-break failure in France in 1959 (killed 500 people), Vaoint dam failure in Italy in 1963 (killed 2600 people), Teton dam failure in Idaho United states in 1976 (killed 11 people and 13000 cattle). Emergency action plans have to be prepared for every dam higher than $20 \mathrm{~m}$ with a reservoir volume over $15 \mathrm{Mm}^{3}$ [5]. Therefore accurate estimates of the flood arrival time, flow depths, velocities are important for emergency planning and flood hazard assessment because of the very least 
margin that we have in contrast to the flooding from rainfall or snowmelt. Since the most important part of flood hazard assessment is the delineation of the flood plain and the identification of high-risk areas [6]. Hence predicting the high-risk areas is possible by drawing the flood inundation maps. However, to predict these quantities we need to solve the governing equations they are unsteady and contain terms of pressure gradient, viscosity which need a lot of boundary conditions making it very difficult to solve them manually for such complex situations. Either, we can use scale-down models but scale-down models can describe a very limited amount of problems with very limited operating conditions. Moreover, scale-down models in cases of dam-break are also not very efficient because replicating the complex bed topography in the laboratory can be a very expansive and laborious job. To do so even for simple dam-break scenarios and non-variant bed topography a lot of technical assistance and financial resources are required. Alternatively, Flood inundation maps are obtained by simulating the flood through the terrain with the given initial and boundary conditions using Numerical Models. Numerical models discretize the partial differential equations and give an approximate solution to the problem. With the help of numerical models we can analyze any fluid dynamics problem for the actual flow domain and virtually any realistic operating conditions.

The discretization techniques that are normally in use are the finite difference method, finite volume method, and finite

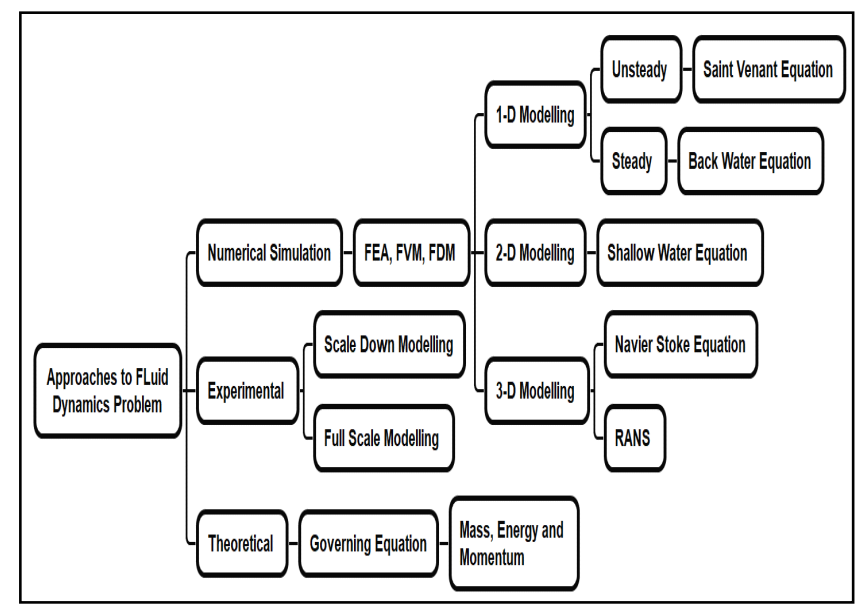

Figure 1: Finding solution to fluid dynamics problems

element method. For this purpose, many numerical modeling tools are used. As the Figure 1 shows we can analyze a problem for all desired quantities and with high resolution in space and time. Numerical models are Quantitative predictions of a flow phenomenon. These models make some approximations to solve the principles that govern the phenomenon and based on that, they have their limitations. [7]

One-Dimensional Hydraulic models use the Backwater equation for steady flow problems and the saint venant equation for unsteady flow problems. The primary assumption of these one-dimensional hydraulic models is that the flow is gradually varied [8]. This means that changes in channel properties, such as cross-section shape, invert level, flow depth, and pressure distribution, are negligible at shorter distances. Which makes it hard for these models to simulate areas of rapid acceleration or deceleration. The numerical solution used by two-dimensional hydraulic models is usually based on a shallow water equation, from which the Saint-Venant equation is derived for unidirectional flow. Traditionally, the mesh has been a fixed-space rectilinear grid with the governing equations solved. But two-dimensional hydraulic models assume that flow is one- or two-dimensional, vertical variations in the flow properties are neglected [9]. Then comes the 3D models which can easily simulate the downstream, lateral, and vertical components of flow.

Robb and Vasquez investigated the capability of two fully three-dimensional computational (3D) fluid dynamics models and one two-dimensional (2D) depth-averaged model. They found out that the results from CFD models (3D) show quite an improvement over those from the depth-averaged model (2D). [4]

Ozmen-Cagatay and Kocaman presented an experimental and numerical investigation of the dam-break flow in the presence of obstacles over initially dry bed conditions. A comparison was made between the shallow water equation, Reynolds's Averaged Navier Stoke Equation, and physical model. The experimental setup contained a rectangular channel $8.9 \mathrm{~m}$ long, $0.3 \mathrm{~m}$ wide, and $0.34 \mathrm{~m}$ high. FLOW-3D was used for numerical investigation solving RANS Equation with k-e Turbulence Model and it was concluded that the shallow water equation is capable of generating free surface profiles and the process requires less CPU time for large computational domains. The measuring technique adopted in the experiment yields accurate results and the RANS model reproduces the flow under investigation with reasonable accuracy while the simple SWE model indicates some discrepancies particularly in predicting the negative wave propagation. [10]

L. Toombes and H. Chanson performed an experiment on the weir and examined the validity of different numerical models. They verified the predictions of the models against physical data. 4 different hydraulic models i.e. FLOW 3D, HEC-RAS, MIKE11, and MIKE 21 were used to simulate flow over a weir and flow in a sloppy channel with a hydraulic jump and found that Flow 3D with its ability to model vertical velocity component, flow accelerations and non-hydrostatic pressure produce accurate results matching the results of the physical model. Moreover, they concluded that the inability of 1-D models to simulate supercritical flow and the 'water column' effect of two-dimensional models can cause significant inaccuracy in model predictions. [11]

Zarein and Naderkhanloo modeled the Dam break flow using 3D mike 3 hydraulic models and modified the common 3D shallow water equations and found that from the results of a 1-hour model evaluation it was observed that the results of his parametric tests were quite similar in comparison with the 
simulated water depths and velocities. Velocities in the profile and plan at the upper layer were higher than in the lower layer which represents the physical phenomena. [12]

Roga and Pandey used two-dimensional turbulent non-premixed combustion model. A standard $k-\omega$ turbulence model was used for modelling turbulence. It was observed from the modelling results that very little amount of $\mathrm{OH}$ were found after combustion. A complete combustion process was modelled using 2D CFD model. [14]

Zarein and Naderkhanloo modeled the Dam break flow using 3D mike 3 hydraulic models and modified the common 3D shallow water equations and found that from the results of a 1-hour model evaluation it was observed that the results of his parametric tests were quite similar in comparison with the simulated water depths and velocities. Velocities in the profile and plan at the upper layer were higher than in the lower layer which represents the physical phenomena. [12]

Rostami and Siosemarde simulated the Dam break of Upper Gotvand Dam using FLOW-3D and found that the flood of the dam break will reach Gotvand City in 6 mins and shoshar city in $10 \mathrm{~min}$ from the dam break time. [5]

George and Nair simulated the dam break of the Thenmala Dam of Kerala state, India using BOSS DAMBRK. As a part of the work, the maximum precipitation and maximum flood have been evaluated using the Gumbel's and Clark's methods respectively. The final analysis is done using BOSS DAMBRK for evaluating the extent of inundation, travel time, and velocity of the downstream wave. They observed that the total time of dam-break flood wave is 35.98 hours and the maximum discharge will be 4589.42 cubic $\mathrm{m} / \mathrm{s}$ corresponding to a max precipitation of $396 \mathrm{~mm}$. [13]

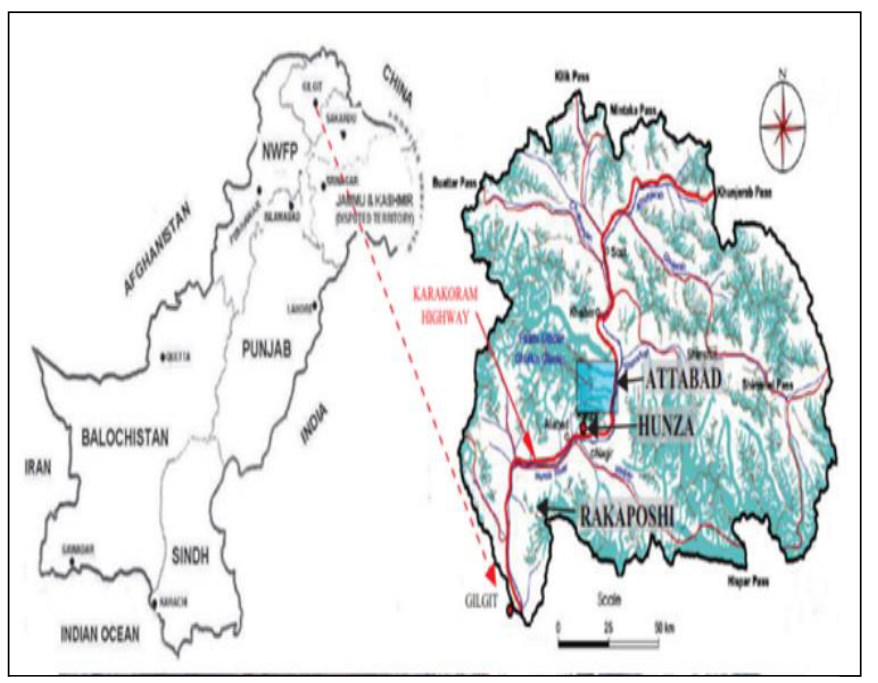

Figure 2: Case Study Location on Map of Pakistan

\subsection{Study Area}

The paper focuses on performing a dam-break flow simulation of Attabad Lake in Pakistan. The lake is formed due to a natural landslide disaster that blocked the Hunza
River and hence forming a lake on the upstream side. A huge landslide happened near Attabad village on the $4^{\text {th }}$ of January in 2010 at $100 \mathrm{~km}$ upstream of the confluence of Hunza and Gilgit rivers as shown in Figure 2.

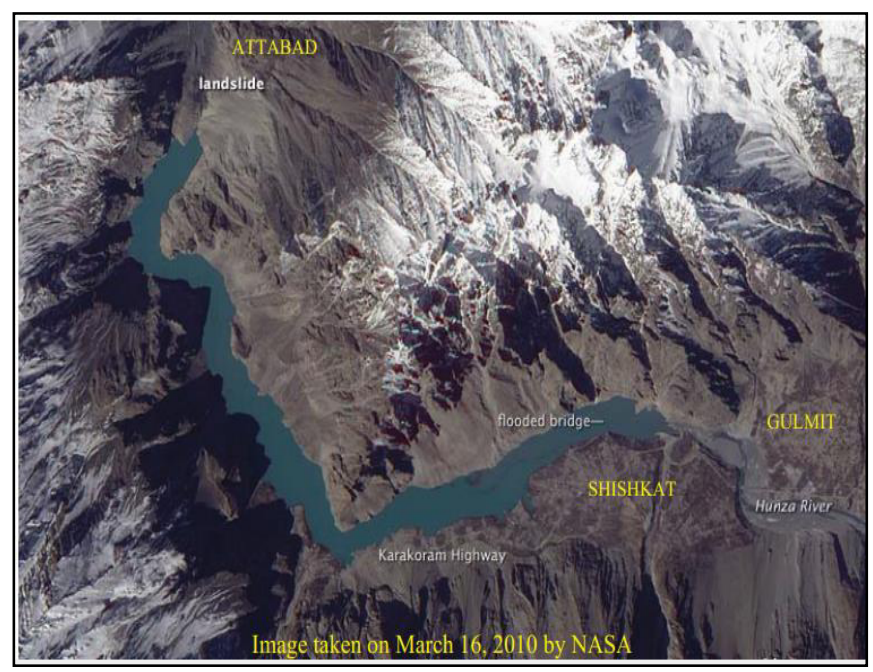

Figure 3: Lake Condition 3 months after Landslide

That caused the death of 20 people, displacing more than 25,000 people. 2 kilometers of the Karakoram Highway was inundated by the Landslide. The height of the debris varies from $126 \mathrm{~m}$ to $210 \mathrm{~m}$ across the Hunza River. The Hunza River was completely blocked as shown in Figure $\mathbf{3}$ as a result, a lake was formed at the upstream side of the Landslide. Immediately after the landslide, water started accumulating upstream of the landslide hence the water surface elevation was continuously going up as a result the upstream villages were all in an alarming situation and were at risk of being drowned by the lake, and the huge accumulation of water produced a high risk of dam burst scenario. So, to drain the water from the lake $24 \mathrm{~m}$ deep and $45 \mathrm{~m}$ wide channel was excavated by Frontier Works Organization (FWO) that decreased the risk of dam burst scenario by $56 \%$. Currently, the capacity of the lake is 305 Million cubic meters with a mean depth of $109 \mathrm{~m}$.

After all efforts from the local agencies the immediate risk of dam break due to overtopping was reduced but still there are many other mechanisms with which the dam can possibly break. Owing to the geophysics and the location of the Attabad lake, it can break because of two reasons (1) Attabad lake is located in Zone 3 as per zonation of seismic activity and is always susceptible to larger earthquakes so the waterlogged material of the landslide causing the impounding of water may lose its strength due to strong ground shaking (liquefaction) and hence the dam may break (2) another landslide into the body of the lake may occur, causing the overflow of water over the impounding material and hence the dam material may breach. Previously the estimate of the break of Attabad Lake has been attempted using the One-dimensional HEC-RAS model. In this study, we analyzed the dam break using a 3D 
hydraulic Model i.e. FLOW-3D. The dam break analysis of the lake will guide in developing flood inundation maps, establishing emergency action plans and flood management models.

Different numerical models are used to make approximations to the governing equations. The reliability of the results depends upon the approximations and the assumptions that are made to solve the governing equation for a particular CFD problem. These governing equations are solved either in 1-D i.e. the properties in the remaining two directions are averaged in 2D or in 3D.

\section{Mathematical Model}

\subsection{FLOW-3D}

The modeling tool that is used in simulating the dam-break of Attabad Lake is "FLOW-3D". FLOW-3D is a CFD software package developed by flow science. It is extensively used throughout the world in a variety of research works. FLOW-3D solves the Reynolds's Averaged Navier-Stokes system of equations in three dimensions to simulate the flow of fluid. FLOW-3D contains models for change in the dynamic properties of the fluid such as viscosity, density, and other hydrodynamic properties of fluids. It uses a trademarked volume-of-fluid (VOF) method to track the free surface.

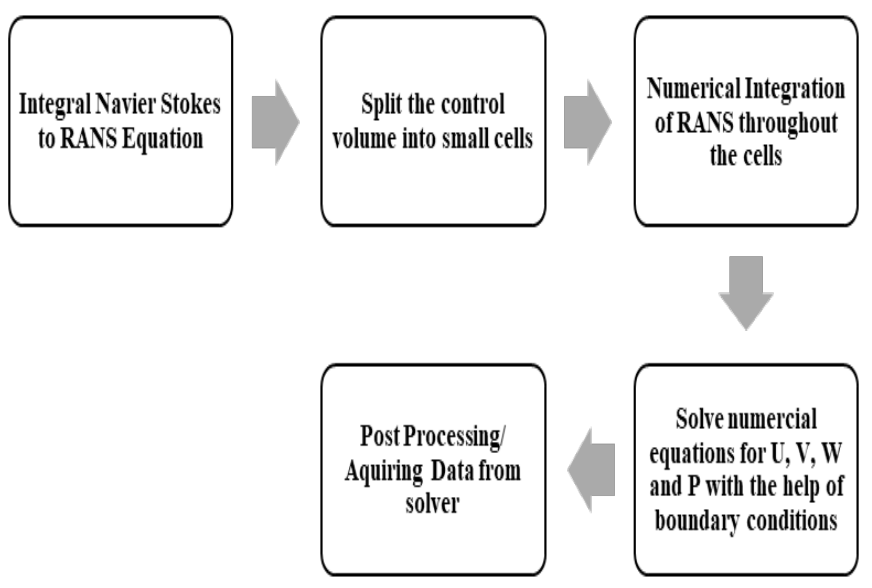

Figure 4: VOF Technique for RANS Equation in FLOW-3D

Registered as TruVOF, the approach provides three important functions for free surface flow: accurate location and orientation of free surfaces within computational cells, accurate tracking of free surface motion through cells, and an accurate boundary condition applied at the free surface interface. The mechanism can be shown in Figure 4.

\section{SOLUTION PROCEDURE}

\subsection{Topography}

Normally the topography can be taken from the DEMs of the particular location in $30 \mathrm{~m}$ resolution. The topography of

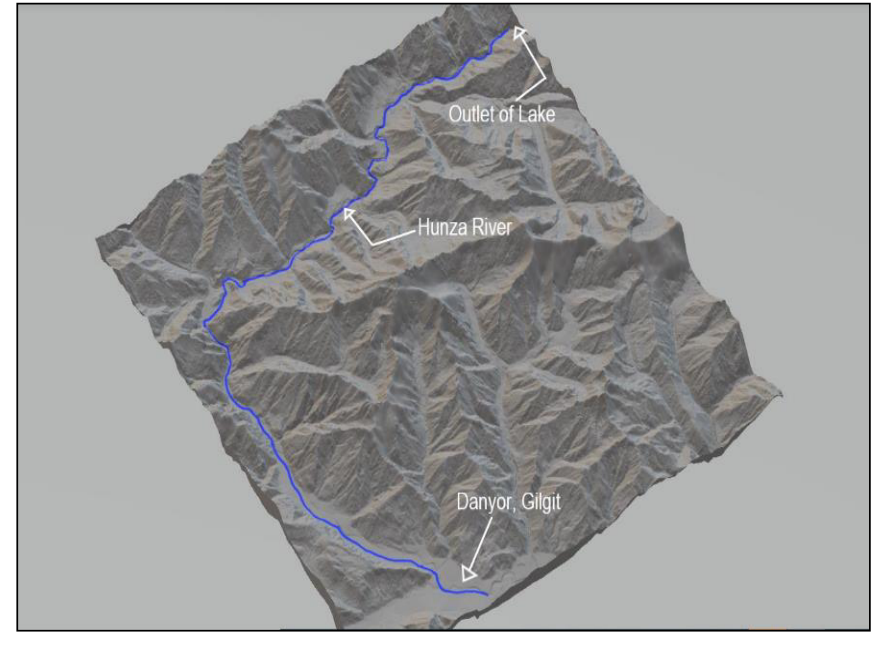

Figure 5: 3D Model from the Merged DEM

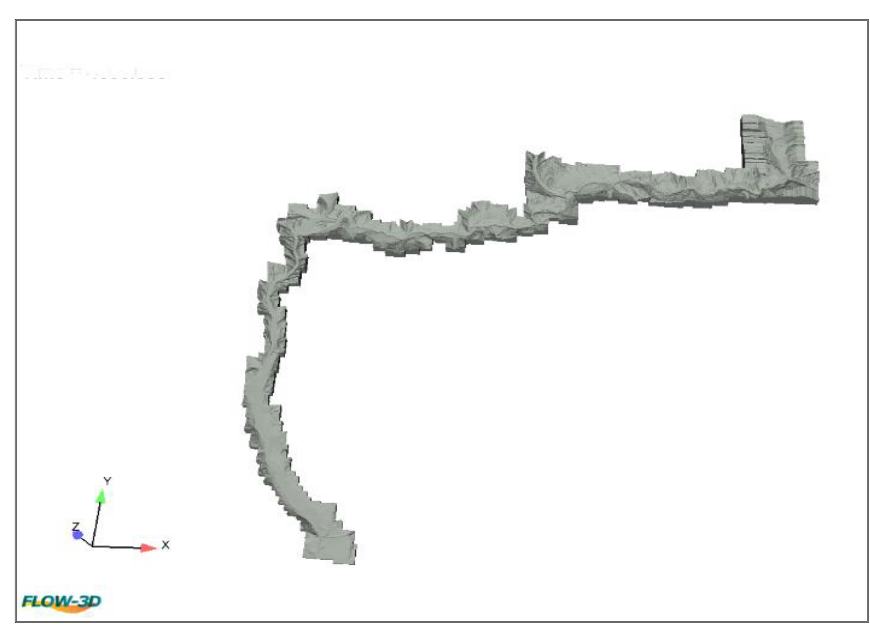

Figure 6: Three Dimensional Model of the Hunza Valley

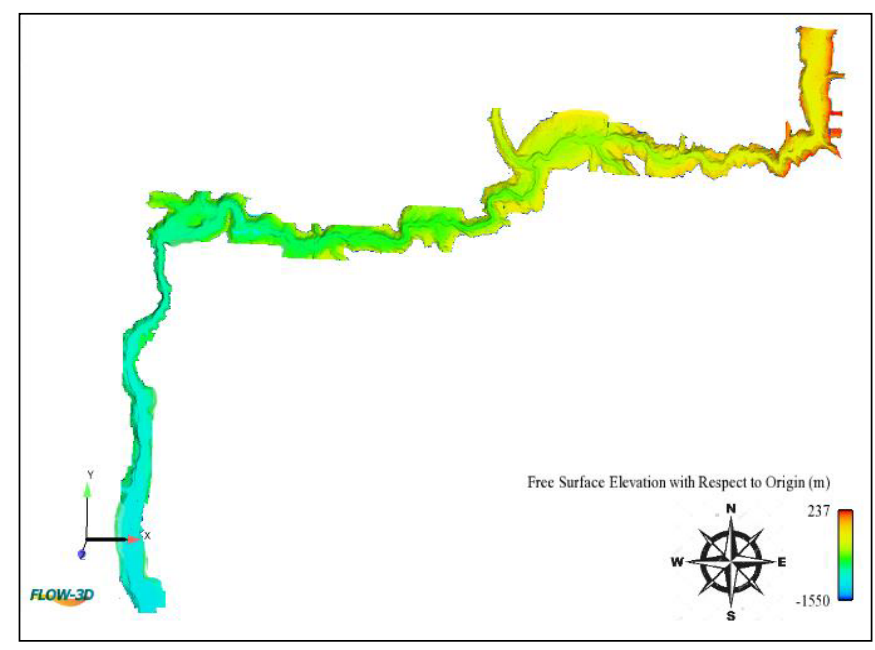

Figure 7: Free Surface Elevation relative to local origin

the underlying terrain was enclosed in 4 ASTER global DEMs that are downloaded from earth explorer, USGS. The DEMs are then merged in ArcGIS to make a single tagged image 
format (.tif) file. FLOW-3D takes the topography as stereo lithography (.stl) file so the resultant tif file is to be converted into .stl format. There is also a utility available in FLOW-3D for the conversion from DEM format to topography (.stl) format but the file that is extracted from the ArcGIS after mosaicking the 4 DEMs has .tif format. The tif file is converted to .stl file through a computer program. The merged DEM was then converted to stereo lithography (.stl) format. As shown in Figure 5 the file is in $3 \mathrm{D}$ and is in .stl format. But as we can see the file represents downstream of the lake. Meshing and applying the equation to the DEM as a whole can lengthen simulation time. Handling the 3D model is not easy due to its larger size. Therefore we have to reduce the size by cutting the terrain and restraining the terrain to area representing only the pathway of Hunza River. So for this purpose, The DEM was edited in Google SketchUp with the help of its handy FREDO tools. The resultant image of the DEM can be seen in Figure 6 and 7.

\subsection{Reservoir Modelling}

As the .stl file is imported to FLOW-3D, Water depth in the DEM was modeled with the help of defining a fluid region. The fluid region was defined in a manner to give a maximum depth of 109 in the lake. The coordinates of the depths and the lake are taken with respect to the local origin. The location of the fluid region along with the spatial distribution of flow depth referenced over Google Earth image can be seen in Figure 8.

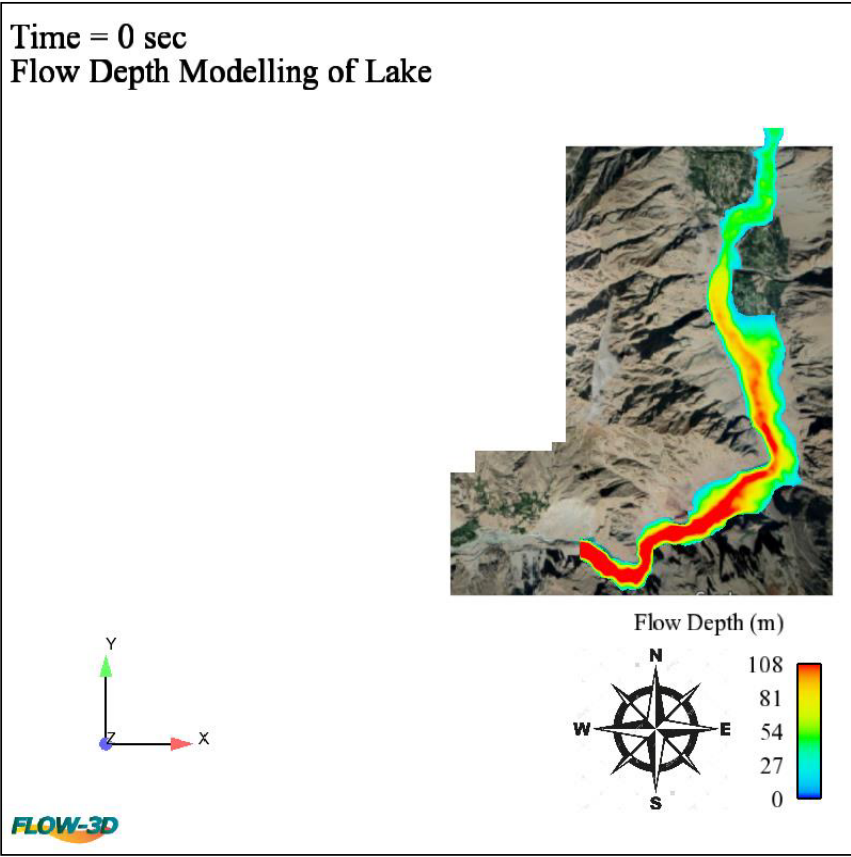

Figure 8: Model of lake referenced over Google Earth Image

\subsection{Probes Installation}

To obtain the data from the analysis we must spot locations in the terrain. These locations are assigned with probes to get the data in FLOW-3D. Probes can either be a line or a point. Point probes are assigned at 15 different locations to derive the fluid properties at those points after simulation. Probes are points at which the model gives us the data output. The data output that we can get from these probes includes Velocity, Hydraulic head, Pressure, Scour, Free surface elevation, Flow depth and other hydraulic parameters of fluid and the topography.

\subsection{Assumptions/Boundary Conditions}

To simulate the Attabad dam-break using FLOW-3D, the following conditions are assumed,

- The soil mass is replaced by an X-plane baffle with the $\mathrm{X}$-Coordinate at -2303 . This baffle will be completely removed as a situation of a dam break.

- The earthen dam is assumed to be completely removed at the instant the dam breaks.

- The base flow of the Hunza River is not considered in the simulation.

- No input discharge to the reservoir is taken into account.

- Manning's $n$ value for the area is assumed to be 0.03 .

- The dam break is instantaneous.

\subsection{Specific conditions (Related to FLOW-3D)}

The following conditions were assumed related specifically to FLOW-3D,

- Total simulation finish time $=4714 \mathrm{sec}(1$ hour $18 \min 34$ sec).

- SI units

- Single fluid modeling (water at $20^{\circ} \mathrm{C}$ )

- Two working models (Viscosity and Gravity Models)

- Gravity $=-9.81 \mathrm{~m} / \mathrm{sec}^{2}$ (Z direction)

- RNG (Re-Normalized Group) turbulence modelling is used to simulate viscosity and Turbulence.

\subsection{Meshing}

The quality of the results depends upon the mesh size. Finer the mesh size greater the accuracy. With finer meshes, the simulation time may increase but the results are accurate. FLOW-3D uses a Rectangular/Cylindrical Cartesian Mesh to apply the governing equations to the domain in which the scenario is enclosed. Initial and boundary conditions are applied to the mesh. In FLOW-3D rectangular mesh is used. So the domain is enclosed in about a total of 15 mesh blocks. Where two meshes coincide, there a continuative boundary condition is used. A continuative boundary condition means 
whatever the scenario is there in the connected mesh block the other mesh block just keeps it continuous. The boundary condition at the junction of the two mesh blocks is marked as "continuative", which means that the numerical scheme is continuative on this boundary and in a case, fluid is passing through this boundary, the flow properties through this boundary will be continuous within the fluid. The result of the meshing of lake is shown in Figure 9.

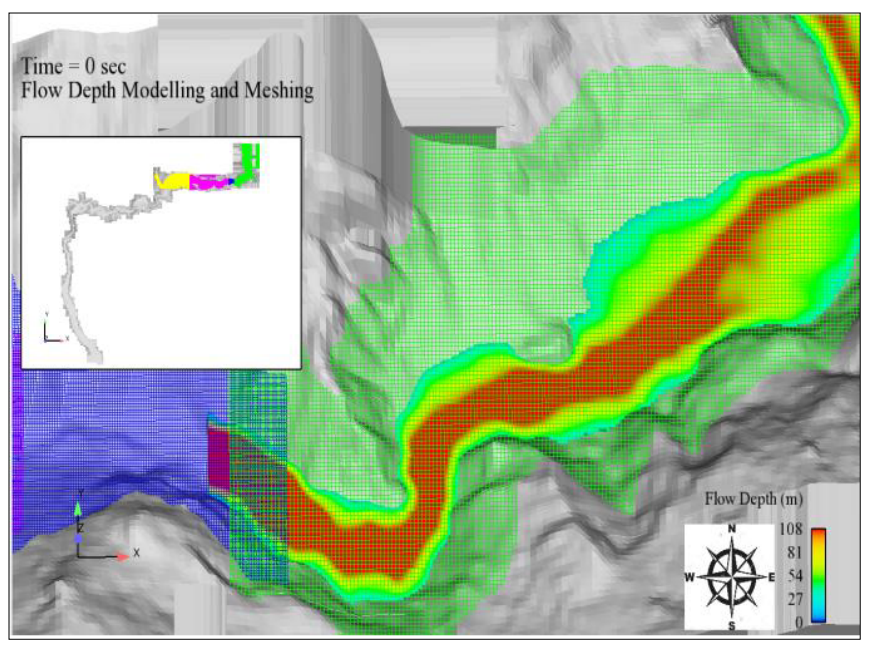

Figure 9: Meshing in the 3D Terrain Model

\subsection{Time stepping}

The initial time step for the history data interval from the numerical solver is $60 \mathrm{sec}$ each. The solver gives history data each $60 \mathrm{sec}$. the history data is calculated at the probes which are used to draw X-Y plots of spatial and temporal changes in particular flow property. History data includes the output from sampling volumes, history probes, flux surfaces, moving object data, and the pressure and shear force output on components. For history data probes are used, a total of 15 probes are installed at different village's locations and the history data is obtained on these probe locations. History probes are located at each village at the bend of the river adjacent to the village.

The basis for the output data is selected as time rather than "fill fraction". The output data that is to be extracted is (1) Velocities (2) Hydraulic Data (3) Turbulent Quantities.

\subsection{Simulation}

After meshing and all the boundary and initial conditions, we are set for the simulations. The whole 4714-sec simulation can't be completed in a single simulation file. We have to split the simulation time into parts of particular simulation times. For this purpose we use restart simulation tool in FLOW-3D to extend the simulation time for the terrain.

\subsection{Post Processing}

All the data was analyzed and the results are obtained in the FLOW SIGHT. Software that is a sub tool of FLOW-3D. In FLOWSIGHT all the data from the probes (velocity vectors, inundation maps, and flow depth hydrographs) is extracted from the simulation files.

\section{RESULTS AND DISCUSSION}

A total of $4714 \mathrm{sec}$ of the simulation was done for the dam break and the flood wave was modeled in the downstream terrain from the point of the dam break. The results obtained from the simulations are

1. Flow Depth Hydrographs

2. Flood inundation maps

3. Velocity Vectors at different time frames after the Dam breaks

\subsection{Summary of the Results}

The data was received from the probes set out at different cross-sections of the villages. The peak discharge, peak depth, time of flood arrival, and time of peak discharge are all important factors for deriving a flood mitigation plan hence all are taken from FLOW-3D in this analysis. We can get the data at any point in the solution domain (mesh) other than the probes. Table 1 represents the summary of the data.

\subsection{Flow Depth Hydrographs}

Hydrographs are important in showing the depth variation at the particular cross-section of the village. Max flow depth occurs at the Ali Abad section due to the retention at the meander bend at the Mutazabad village where water lost

much of its kinetic energy because it produced a centrifugal force that caused accumulation of water at the outer bend at Aliabad and since then the flow depth at the sections decreases gradually as we can see 86 at Miachar then 80,62 and 50 at Minapin, Ghulmet and thol respectively after the uniformity in flow length. The depth starts rising again due to the accumulation of water starting at Jafarabad reaching $70 \mathrm{~m}$ due to the meander bend at Sikandar Abad. But eventually, the depth starts to fall off from the chalat after entering into a wide and open area. The flow depth hydrographs are given in Figure 10. The spatial and temporal change in depth and potential energy of water that occurred throughout the flow of water from Karim Abad to Nomal Bridge can be estimated from the flow depth hydrographs shown in Figure 10.

In the Figure 11, the output discharge hydrograph at the location Karim Abad, the $2^{\text {nd }}$ modeled cross-section, and the last modeled downstream cross-section, Nomal Bridge is shown. The peak discharge is reduced from 472404 to 146710 $\mathrm{m}^{3} / \mathrm{sec}$ while flowing from one cross-section to another respectively. The attenuation can be estimated from the fact that the arrival time at the Karim Abad section is 5 mins after the dam break while the time of arrival at Nomal bridge is 68 mins. As we can see the rising limb of the hydrograph for the Nomal Bridge is approximately at the falling limb of the hydrograph of the first modelled cross-section. Though the hydrograph at the cross-section of the Nomal Bridge seems to be incomplete but is past its peak right about at the end of the Karim Abad hydrograph. But we can assume that we will have a lengthened falling limb of the hydrograph of the Nomal- 


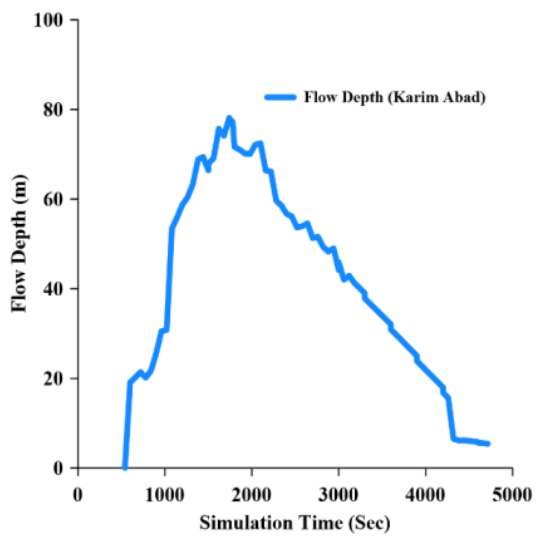

(A)

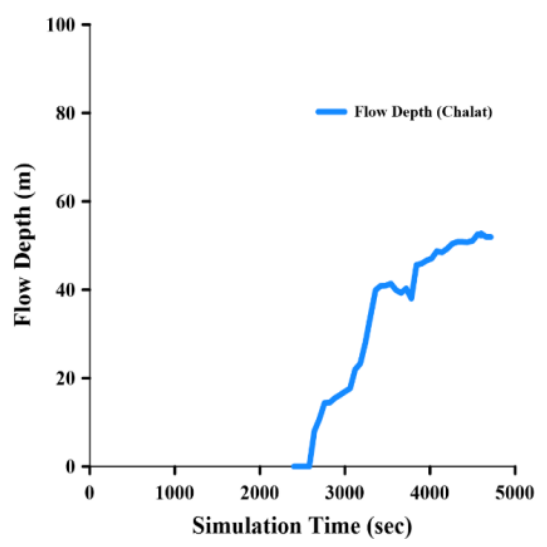

(D)

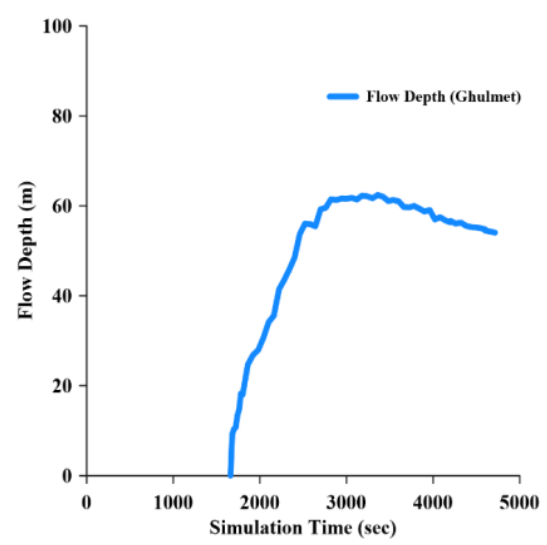

(B)

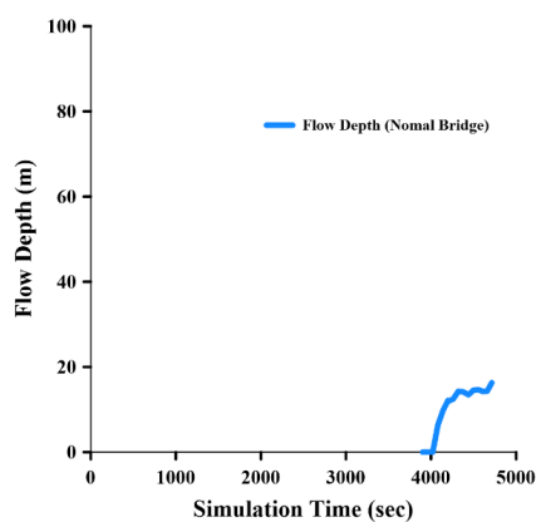

(E)

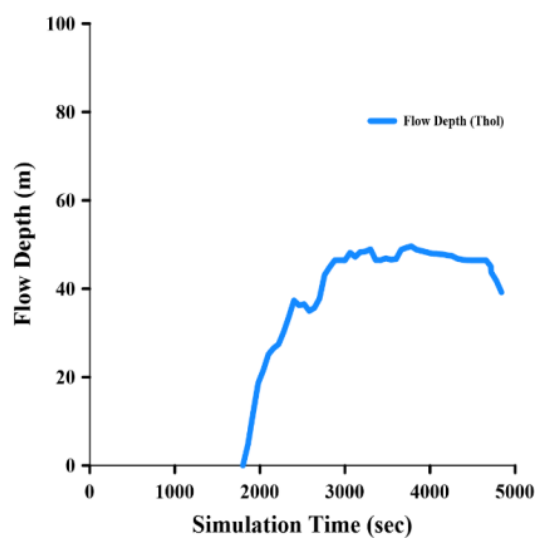

(C)
Figure 10: Flow Depth Hydrographs of the downstream villages (A) Karim Abad (B) Ghulmet (C) Thol (D) Chalat (E) Nomal

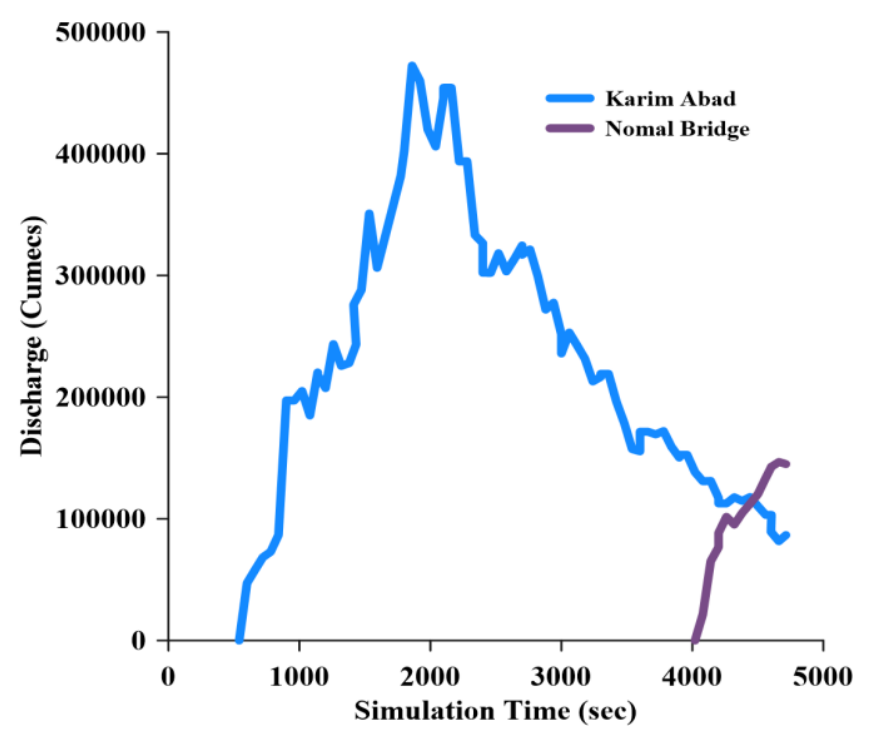

Figure 11: Flow Hydrograph at Karim Abad and Nomal Bridge
Bridge having a higher base time because of the slow arrival of the attenuated water mass throughout the valley.

\subsection{Flood Inundation Maps}

The Flood inundation maps show the extent of flooding that could happen if the dam breaks. Flood inundation maps are created with the help of reference images of Google Earth that are textured on the DEMs topography in FLOW-3D For flood inundation maps, first we model the Peak Flow Depth at a particular section that happens at a correspondent simulation time. For example, the flood inundation map for the Karim Abad village is derived for the simulation time of $1800 \mathrm{sec}$ because max flow depth at this section occurs at $1800^{\text {th }} \mathrm{sec}$ of the simulation time. Similarly then by drawing the Flow Depth Contours we know the exact depth at the particular location of the particular section. Flood inundation maps are derived for max depth at the particular probe installed at the village cross-section in the topography. The flood inundation map of Karim Abad shows in Figure 11 that the smaller villages of Ganish, Altit, and Garlet are at higher risk of inundation than most of the Karim Abad, Ali Abad, and Sumayar areas which are at more elevated areas than these villages. The maximum section of the village of Hassan abad situated under the flood plain between the villages of Aliabad and Miachar are at greater risk of inundation. 
In Figure 12 we can see that the part of Sikandar Abad agricultural fields and most of the Miaun Village as modeled are at risk of inundation. The Miaun village is situated on the right bank of the Hunza River opposite to thol. The flood arrival time for Miaun village is 31 min which can be regarded as enough time for the population of Miaun to evacuate to near situated safer areas subject to availability. While for most of the villages after Ghulmet the flood wave is contained by the flood plain and the villages in this section other than Miaun are comparatively at lower risk. While Figure 13 shows that a large part of the Sonikot road and Karakoram highway near the chalat village are at greater risk of inundation. Max part of the chalat village situated at the right bank of the Hunza River is completely inundated as modeled. While engulfing most of the chalat valley road and also the Karakoram highway at the meander bend at the end of the chalat valley. The arrival time of flood wave at the chalat valley is $44 \mathrm{~min}$ which is enough time for the evacuation of the population to safer sites.

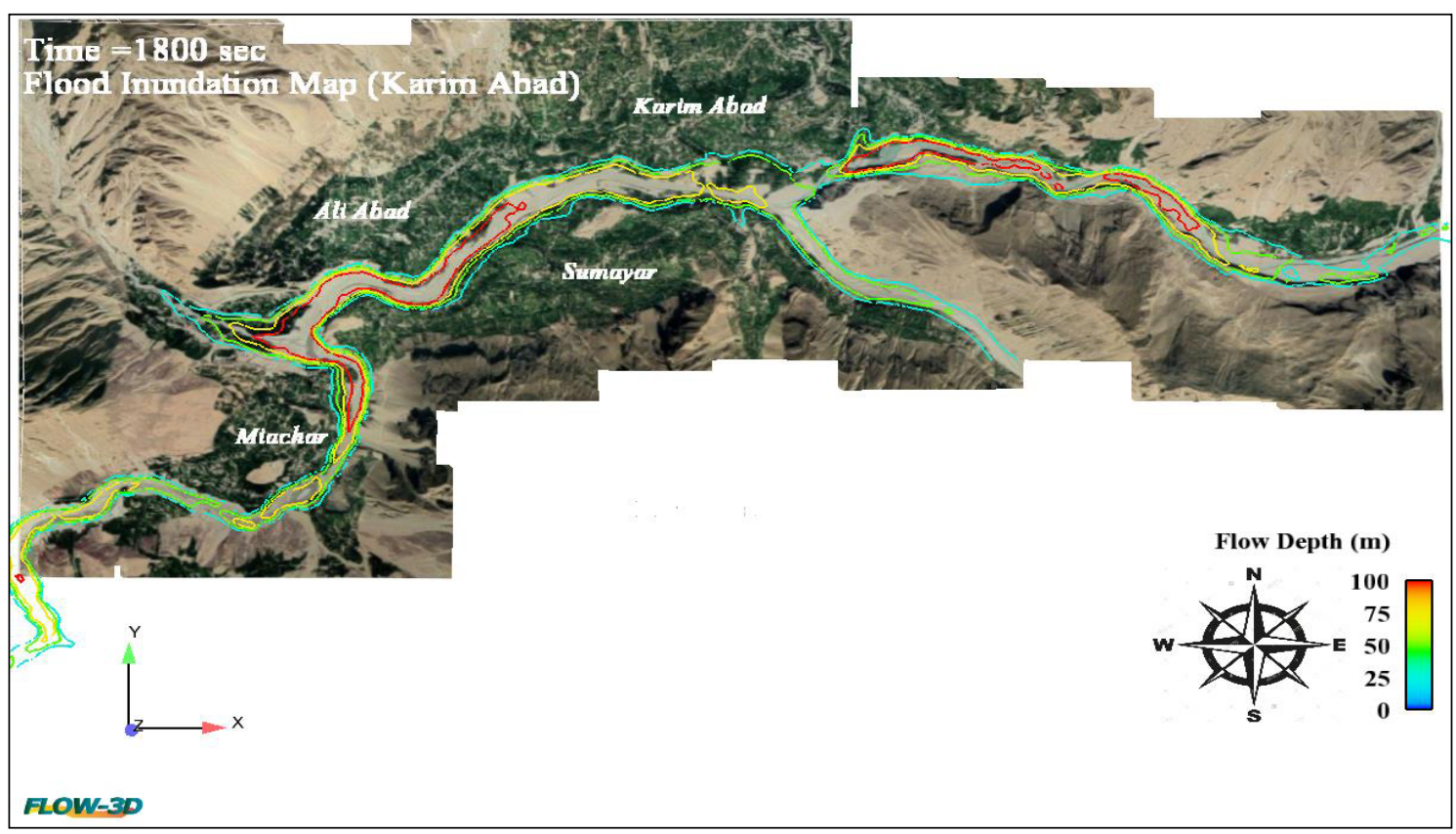

Figure 12: Flood Inundation Map of Karim Abad

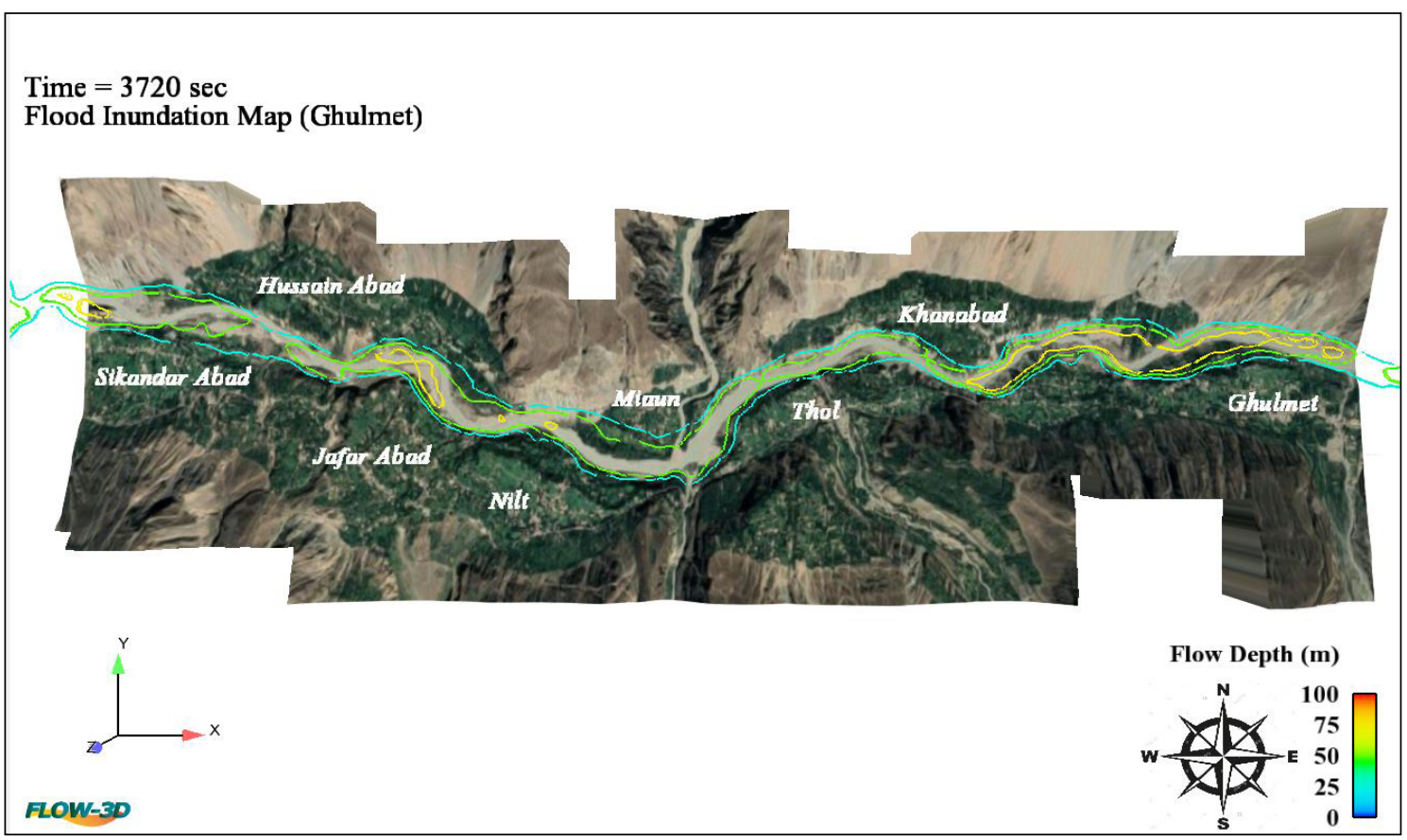

Figure 13: Flood Inundation Map of Ghulmet 


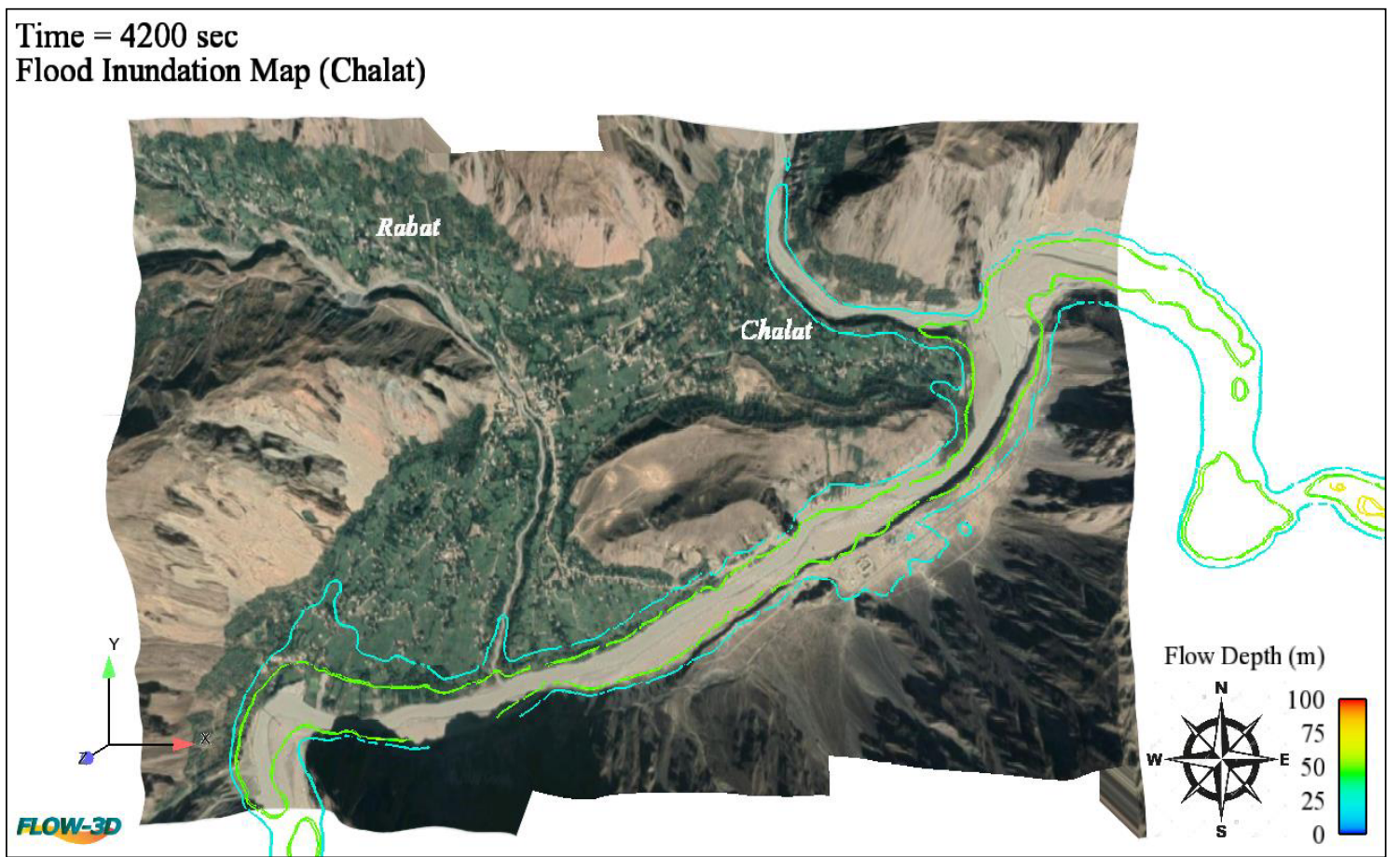

Figure 14: Flood Inundation Map of Chalat

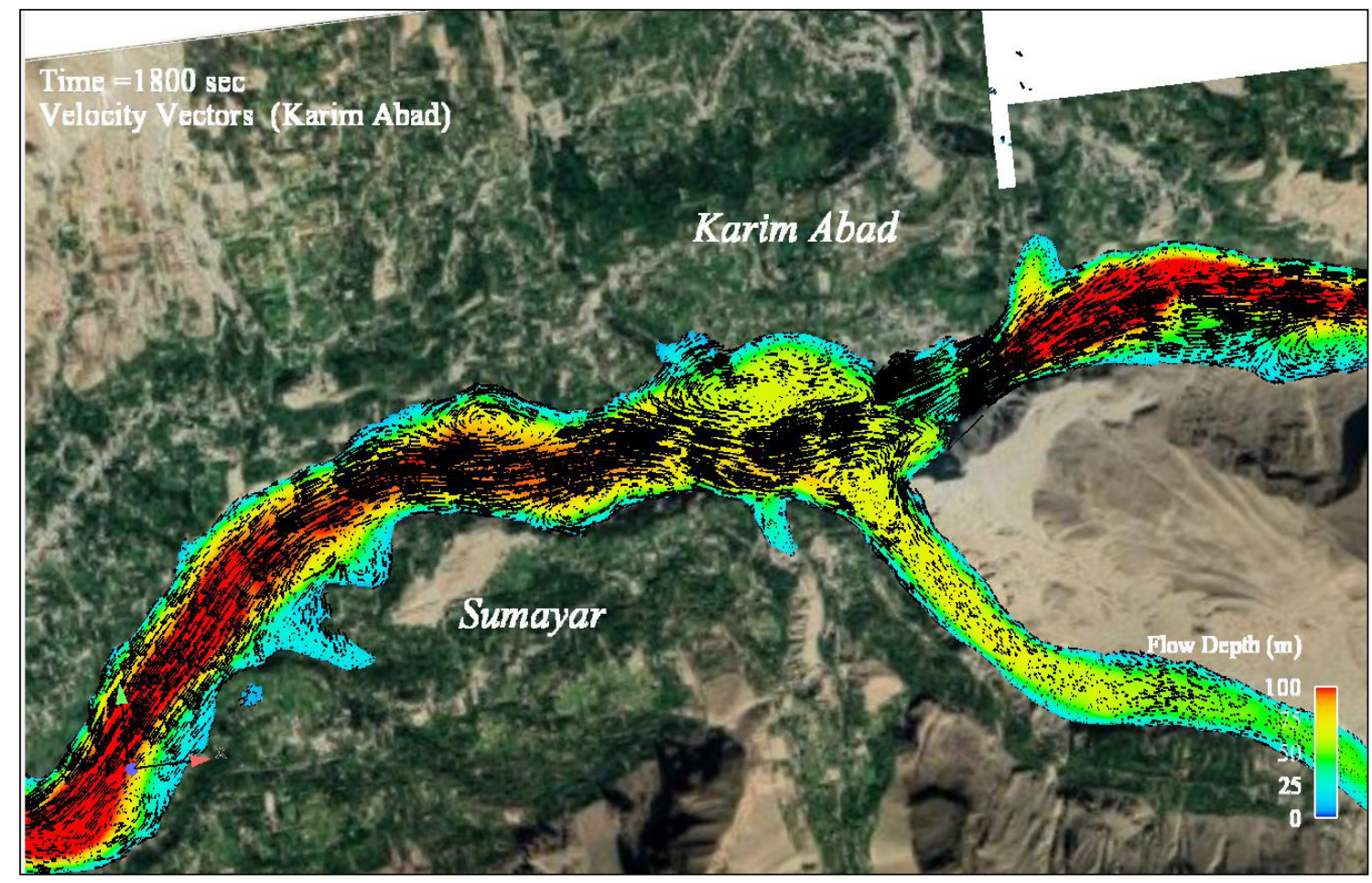

Figure 15: Velocity Vectors of flow at Karim Abad 


\subsection{Velocity Vectors}

From the velocity data obtained from the probes, we know that the highest velocity in the main channel of the Hunza River due to flood wave occurred at Ahmedabad just below the dam break site while the minimum velocity occurs at Jafarabad, Sikandar abad, and Chalat which is 21,21 , and 22 $\mathrm{m} / \mathrm{s}$ respectively. That is due to the huge meander bend that intercepts the flow while entering into chalat valley and the water entering into a wider area in chalat. After the chalat valley, the velocity again increases going through the Hunza River. Which shows that the flood wave entered a choked valley after the chalat and thus the velocity starts increasing again.

The flow while going through the meander bend just before the chalat valley undergoes centrifugal action and the wave is split after hitting the mountain as the velocity vectors at the start of the chalat village can be seen in Figure 17.

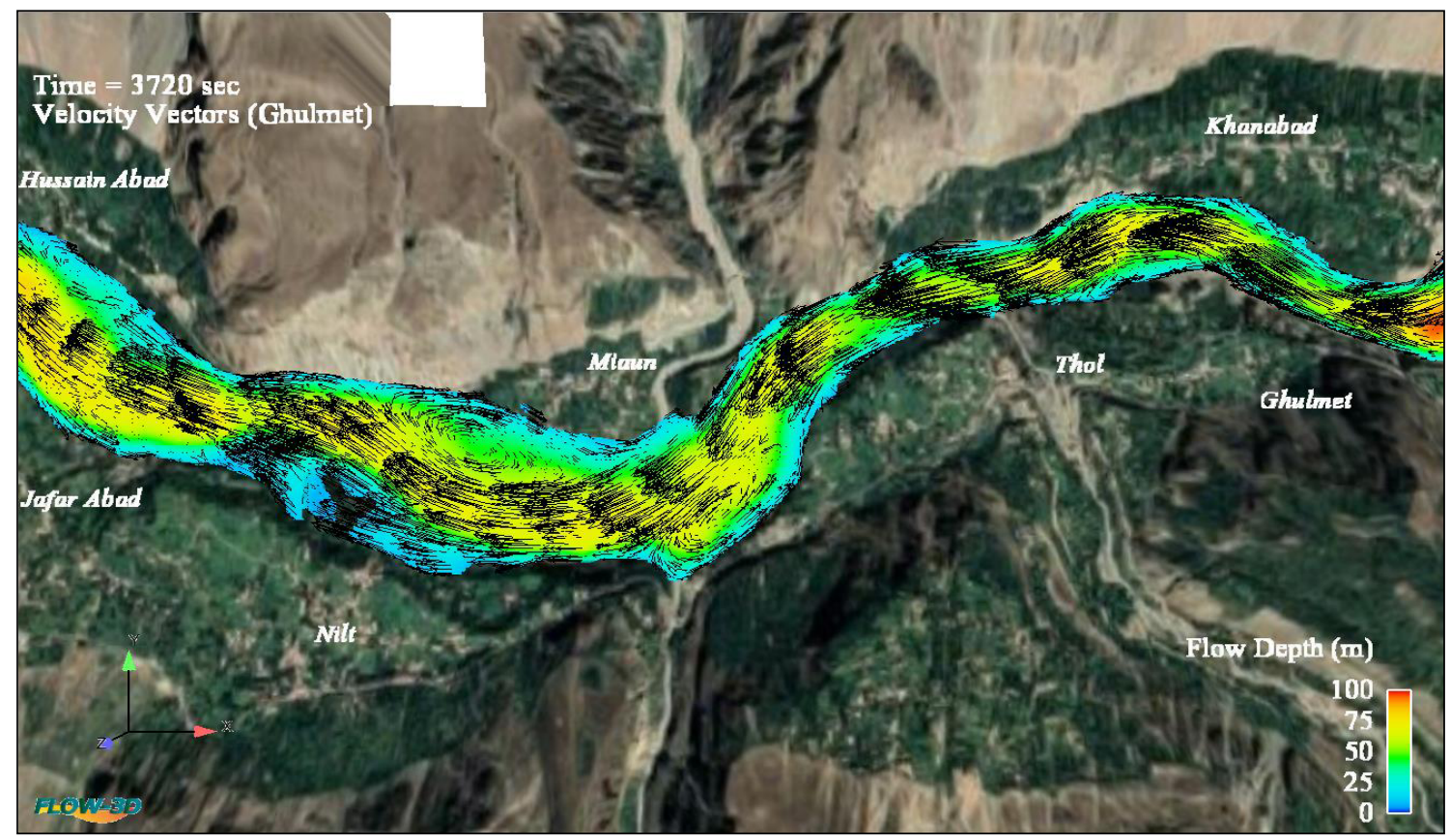

Figure 16: Velocity Vectors of Flow at Ghulmet

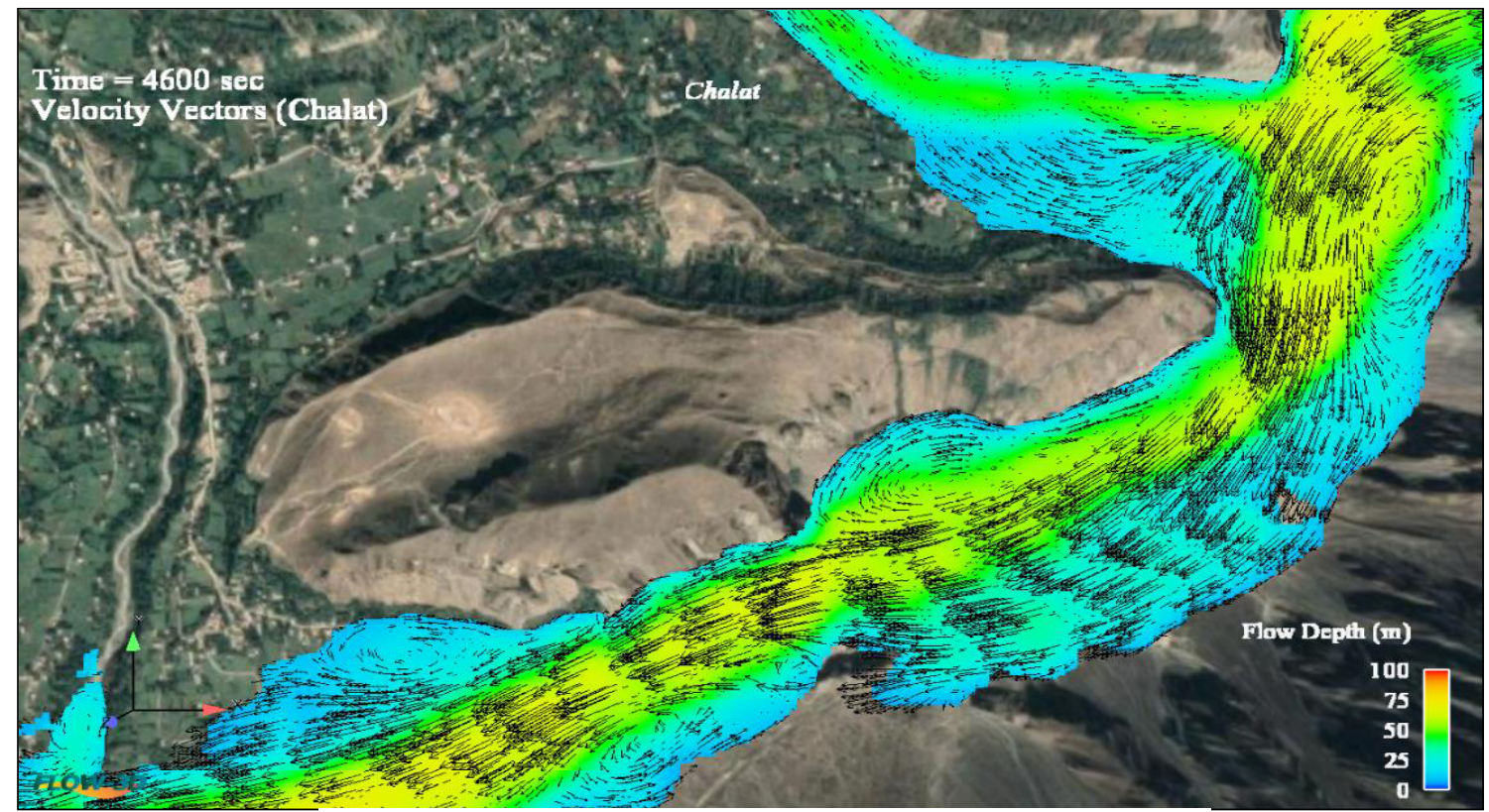

Figure 17: Velocity Vectors of Flow at Chalat 
Wasim Karam et al., International Journal of Emerging Trends in Engineering Research, 9(6), June 2021, 703 - 714

Table 1: Results Summary

\begin{tabular}{|c|c|c|c|c|c|c|c|c|}
\hline S. No & Village Name & $\begin{array}{c}\text { Peak } \\
\text { Discharge } \\
\left(\mathrm{m}^{3} / \mathbf{s e c}\right)\end{array}$ & $\begin{array}{c}\text { Peak } \\
\text { Depth } \\
\text { (m) }\end{array}$ & $\begin{array}{c}\text { Time } \\
\text { to } \\
\text { Peak } \\
\text { Depth } \\
\text { (sec) }\end{array}$ & $\begin{array}{c}\text { Max } \\
\text { Velocity } \\
\text { (m/sec) }\end{array}$ & $\begin{array}{c}\text { Flood } \\
\text { Arrival } \\
\text { Time } \\
(\mathrm{sec})\end{array}$ & $\begin{array}{c}\text { Time to } \\
\text { Peak } \\
\text { Discharg } \\
\text { e } \\
\text { (sec) }\end{array}$ & $\begin{array}{c}\text { Depth at } \\
\text { Peak } \\
\text { Velocity } \\
\text { (m) }\end{array}$ \\
\hline 1 & Ahmed Abad & 472085 & 48 & 1560 & 44 & 300 & 1773 & 6 \\
\hline 2 & Karim Abad & 471405 & 78 & 1800 & 29 & 600 & 1860 & 21 \\
\hline 3 & Ali Abad & 378971 & 92 & 2520 & 28 & 720 & 2100 & 10 \\
\hline 4 & Miachar & 320641 & 86 & 3060 & 33 & 1260 & 2280 & 5 \\
\hline 5 & Minappin & 304174 & 80 & 2100 & 29 & 1380 & 2760 & 8 \\
\hline 6 & Ghulmet & 288524 & 62 & 3660 & 31 & 1680 & 2820 & 44 \\
\hline 7 & Thol & 275236 & 50 & 3780 & 33 & 1860 & 3420 & 36 \\
\hline 8 & Jafar Abad & 273109 & 70 & 3720 & 21 & 2100 & 3720 & 34 \\
\hline 9 & Sikandar Abad & 255163 & 68 & 3720 & 22 & 2160 & 4080 & 5 \\
\hline 10 & Chalat Bridge & 234487 & 53 & 4600 & 22 & 2640 & 4560 & 16 \\
\hline 11 & Jaglot & 215864 & 49 & 4080 & 25 & 3240 & 4600 & 43 \\
\hline 12 & Rahim Abad & 159437 & 35 & 4660 & 25 & 3660 & 4714 & 23 \\
\hline 13 & Nomal Bridge & 146710 & 15 & 4500 & 28 & 4080 & 4660 & 14 \\
\hline
\end{tabular}

\section{LiMitations:}

Every model has its limitation based on the assumptions that it takes to solve the basic principle equation. The uncertainty in the solution of dam break problem using CFD arises initially due to the resolution of the Bed topography derived from the dam break, it is quite hard to replicate it because of the variant bed topography and also the change in the density of the water with time as it flows downstream. These limitations have a direct impact on the results of the solution such as flood travel time and flood inundation maps. Since to make the results more reliable high resolution, newly developed satellite data should be used. Though the results are key in the identification of areas that are at risk if the Attabad Lake is breached but the calculated discharges, travel time of wave, water depths, and Velocities should only be used as a guide in future studies and emergency flood management practices. Manning's n value cannot be replicated with ultimate accuracy in any flow problem and for such large-scale problems like Dam-Break DEM and its resolution, initially assuming the dam to break instantaneously while we are not certain about the dam failure mechanism and accurately replicating the Manning's $n$ value directly alter the simulation results.

\section{CONCLUSIONS}

Dam break causes heavy damages to infrastructure, landscapes, agriculture, and the environment but the

prediction of the parameters like inundation maps and estimates arrival times can never be completely accurate because no single model can fully explain any particular complex scenario like a dam break. Every model has its limitations. Also, the uncertainty of the failure mechanism of the breaching process of the embankment material, though the process in this study was not taken into account, makes the results less reliable. However, 3D CFD Models do solve most of the problems associated with the assumptions to the models but it does that by the cost of lengthened simulation time and higher range of data input. However, the results of the CFD models also depend upon the resolution of the topographic data i.e. Resolution of the DEM, incorporation of the land cover, and properties of water i.e. density of the flood wave as it flows downstream, etc. Using the FLOW-3D CFD model, flood inundation maps, velocity vectors, and flow depth hydrographs for the dam break of Attabad lake were plotted. Results of the simulations show that the peak depth at various sections of the villages downstream of the lake caries between 92 to $15 \mathrm{~m}$. These values indicate higher inundation extents as shown in inundation maps of the villages. The peak velocities vary between 44 to $21 \mathrm{~m} / \mathrm{sec}$ it indicates higher shear stress at the downstream valley and through the sections where the flood passes can experience an extreme washout of 
agricultural land, residencies, and markets and can danger the lives of the people situated in the valley downstream. The arrival time varies between 5 to $68 \mathrm{~min}$ at villages Ahmed Abad and Nomal respectively. This indicates that the villages nearer to the dam break don't have enough time to evacuate although thanks to attenuation that the other downstream villages have got enough time to evacuate the vulnerable areas. The model results can play a key role in risk analysis and flood management practice in the identification of the vulnerable areas to the flood wave resulting from the failure of the embankment dam of Attabad Lake.

\section{ACKNOWLEDGEMENTS:}

The authors would like to acknowledge the facilitation from Department of Civil Engineering, Abasyn University Peshawar, Pakistan. The assistance provided by Engr. Faisal Rehman, Assistant Professor Department of Civil Engineering, UET Peshawar, Pakistan in terrain modelling is highly appreciated.

\section{REFERENCES}

[1]. Zhang, L. \& Peng, M. \& Chang, D.S. \& Xu, Y. (2015). Dam Failure Mechanisms and Risk Assessment, First Ed. John Wiley and Sons, Singapore $473 \mathrm{pp}$. 10.1002/9781118558522.

[2]. T. L. Wahl, "Dam Breach Modeling - an Overview of Analysis Methods," 2nd Jt. Fed. Interagency Conf. Las Vegas, NV, pp. 1-12, 2010.

[3]. Khosravi K. "Dam Break Analysis and Flood Inundation Mapping : The Case Study of Sefid-Rud Dam," no. August 2019. DOI: 10.1016/B978-0-12-815998-9.00031-2

[4]. Robb, D. M., \& Vasquez, J. A. (2015). Numerical simulation of dam-break flows using depth-averaged hydrodynamic and three-dimensional CFD models. 22nd Canadian Hydrotechnical Conference, (June).

[5]. Mohammad Rostami, M. S. (2015). Human Life Saving by Simulation of Dam Break using Flow-3D. Trend in Life Sciences, 4(3), 308-316

[6]. Gharbi, M., Soualmia, A., Dartus, D., \& Masbernat, L. (2016). Comparison of 1D and 2D hydraulic models for floods simulation on the Medjerda River in Tunisia. Journal of Materials and Environmental Science, 7(8), 3017-3026. https://doi.org/10.1080/153

[7]. Andrei, A., Robert, B., \& Erika, B. (2017). Numerical Limitations of 1D Hydraulic Models Using MIKE11 or HEC-RAS software - A case study of Baraolt River, Romania. IOP Conference Series: Materials Science and Engineering, 245(7). https://doi.org/10.1088/1757-899X/245/7/072010

[8]. Henderson, F.M. (1966). Open Channel Flow. MacMillan Company, New York, USA, P. No 304-313

[9]. Betsholtz, A., \& Nordlöf, B. (2017). Potentials and limitations of 1D, 2D and coupled 1D-2D flood modeling in HEC-RAS. Lund University, 128. https://doi.org/10.1016/S0300-9440(03)00139-5

[10]. Ozmen-Cagatay, H., \& Kocaman, S. (2011). Dam-break flow in the presence of obstacle: Experiment and CFD simulation. Engineering Applications of Computational Fluid Mechanics, 5(4), 541-552. https://doi.org/10.1080/19942060.2011.11015393

[11].Toombes, L., \& Chanson, H. (2011). Numerical Limitations of Hydraulic Models. 10th Hydraulics Conference, (July), 2322-2329. https://doi.org/10.1016/j.jalz.2016.06.1613

[12].Zarein, M. (2015). Modeling Dam-Break Flows Using a 3d Mike 3 Flow Model, (January).

[13].George, A. C., \& Nair, B. T. (2015). Dam Break Analysis Using BOSS DAMBRK. Aquatic Procedia, 4(Icwrcoe), 853-860. https://doi.org/10.1016/j.aqpro.2015.02.10

[14]. S. Roga and K. M. Pandey, "Computational Analysis of Supersonic Flow Regime Using Ramp Injector with Standard K- $\omega$ Turbulence Model”. World Academy of research in Science and Engineering, vol. 2, no. 1, pp. 31-40, 2013.http:// doi.org/10.1.1.348.5862. 